\title{
Prostaglandin F2 $\alpha$ regulates the expression of uterine activation proteins via multiple signalling pathways
}

\author{
Chen Xu* Xingji You*, Weina Liu, Qianqian Sun ${ }^{1}$, Xiaoying Ding ${ }^{1,2}$, Ying Huang ${ }^{2}$ and Xin Ni \\ Department of Physiology, Second Military Medical University, 800 Xiangyin Road, Shanghai 200433, China, \\ ${ }^{1}$ Department of Obstetrics and Gynecology, Changhai Hospital, Shanghai, China and ${ }^{2}$ Maternity and Child Health \\ Hospital of Pudong New District, 599 Hongfeng Road, Shanghai 201206, China
}

Correspondence should be addressed to X Ni; Email: nixin@smmu.edu.cn or to be Y Huang; Email: stassi22@163.com

${ }^{*}(\mathrm{C} \mathrm{Xu}$ and $\mathrm{X}$ You contributed equally to this work)

\begin{abstract}
Prostaglandin F2 $\alpha$ (PGF2A) has multiple roles in the birth process in addition to its vital contractile role. Our previous study has demonstrated that PGF2A can modulate uterine activation proteins (UAPs) in cultured pregnant human myometrial smooth muscle cells (HMSMCs). The objective of this study was to define the signalling pathways responsible for PGF2A modulation of UAPs in myometrium. It was found that PGF2A stimulated the expression of (GJA1) connexin 43 (CX43), prostaglandin endoperoxide synthase 2 (PTGS2) and oxytocin receptor (OTR) in cultured HMSMCs. The inhibitors of phospholipase C (PLC) and protein kinase C (PKC) blocked PGF2Astimulated expression of CX43. The inhibitors of ERK, P38 and NFKB also blocked the effect of PGF2A on CX43 expression, whereas PI3K and calcineurin/nuclear factor of activated T-cells (NFAT) pathway inhibitors did not reverse the effect of PGF2A on CX43. For PTGS2 and OTR, PLC, PI3K, P38 and calcineurin/NFAT signalling pathways were involved in PGF2A action, whereas PKC and NF $K B$ signalling were not involved. In addition, PGF2A activated NFAT, PI3K, NFKB, ERK and P38 signalling pathways. Our data suggest that PGF2A stimulates CX43, PTGS2 and OTR through divergent signalling pathways.

Reproduction (2015) 149 139-146
\end{abstract}

\section{Introduction}

During pregnancy, human myometrium undergoes structural and functional changes from a relatively quiescent state during most of gestation to contractile state at end of pregnancy. Such changes are associated with the expression of a group of proteins known as the uterine activation proteins (UAPs) which includes (GJA1) connexin 43 (CX43), prostaglandin endoperoxide synthase 2 (PTGS2), ion channels and the receptors of uterotonic agonists such as oxytocin receptor (OTR) and prostaglandin F2 $\alpha$ (PGF2A) receptor (PTGFR) (Fuchs et al. 1995, Challis et al. 2000, Kamel 2010). Thus, understanding the mechanisms responsible for controlling the expression of these proteins during pregnancy would gain deep insights into the mechanisms underlying the onset of human parturition.

PGs, which are produced within the intrauterine tissues of pregnancy, play important roles in all the physiological processes of parturition, but the most studied is myometrial contraction (Caldwell et al. 1973, Challis et al. 2000, Olson 2003). Elevated uterine PGs or enhanced sensitivity of the myometrium to PGs leads to contractions and labour (Romero et al. 1996, Challis et al. 2000). Among the family of PGs, PGF2A increases the intracellular calcium concentration by stimulating the release of stored calcium, which produces a phasic contraction that permits blood flow to the foetus between contractions and optimises the ability of the uterus to expel the foetus (Luckas et al. 1999). It has been demonstrated that the level of PGF2A in maternal plasma remains higher before the onset of labour compared with the first stage of labour, and it is not significantly changed around parturition (Kinoshita et al. 1977). A number of studies demonstrate that PGF2A is involved in many events during pregnancy (Christiaens et al. 2008, Sykes et al. 2014). Our previous study has shown that PGF2A upregulates CX43, PTGS2 and OTR whereas downregulates PTGFR expression in human pregnant myometrium (Xu et al. 2013), suggesting that PGF2A is involved in uterus activation for labour.

PTGFR, a member of G protein-coupled receptor superfamily, mainly couples to GQ protein and subsequently activates phospholipase C (PLC) $\beta$, leading to an increase in intracellular $\mathrm{Ca}^{2+}$ level and activation of protein kinase $\mathrm{C}(\mathrm{PKC})$, phosphatidylinositol-3-kinase (PI3K) and ERK1/2 (Luckas et al. 1999, Sales et al. 2009, 
Wallace et al. 2011, Kondo et al. 2012). So far, there is no study regarding intracellular signalling pathways of PGF2A modulating various UAPs in pregnant myometrium. Thus, we used cultured pregnant human myometrial smooth muscle cells (HMSMCs) as a model to explore the possible signalling pathways responsible for PGF2A modulation of CX43, PTGS2 and OTR expression.

\section{Materials and methods Culture of HMSMCs}

HMSMCs were isolated from lower segment myometrial biopsies which were obtained from pregnant women who underwent elective cesarean at term. This study was approved by the specialty committee on ethics of biomedicine research, Second Military Medical University, Shanghai, China, and informed consent was obtained from all the patients who participated in this study. HMSMCs were cultured as described previously (Xu et al. 2011). Briefly, myometrial pieces were incubated with phenol-red-free DMEM, containing $1 \mathrm{mg} / \mathrm{ml}$ collagenase type II (Invitrogen), and $1 \mathrm{mg} / \mathrm{ml}$ deoxyribonuclease I (Invitrogen) at $37^{\circ} \mathrm{C}$ for $45 \mathrm{~min}$. Following filtration, the cell suspension was centrifuged at $600 \mathrm{~g}$ for $10 \mathrm{~min}$, and the cell pellet was resuspended in DMEM, containing $10 \%$ FCS, penicillin $(100 \mathrm{U} / \mathrm{ml})$ and streptomycin $(100 \mathrm{mg} / \mathrm{ml})$. The cells were then plated into $25-\mathrm{cm}^{2}$ flasks and kept at $37{ }^{\circ} \mathrm{C}$ in $5 \% \mathrm{CO}_{2}-95 \%$ air humidified atmosphere until confluent ( $\sim 2$ weeks). The purity of myocyte cultures was assessed by immunocytochemistry using smooth muscle $\alpha$-actin MAB (Sigma-Aldrich). All experiments were performed with these cells at passage 2 . The cells were placed in six-well plates with DMEM containing $10 \%$ FCS. Following growth to $\sim 80 \%$ confluence, some of the cells were changed to DMEM without FCS but containing various concentration of PGF2A (SigmaAldrich) in the presence or absence of the inhibitors of various kinases including U73122, chelerythrine, PD98059, LY294002, CsA, Inca-6, trans-retinoic acid (RA), SB202190 and pyrrolidine dithiocarbamate (PDTC) and then incubated for $24 \mathrm{~h}$. The vehicle control was treated with the same volume of solvent (ethanol, $\leq 0.1 \% \mathrm{v} / \mathrm{v}$ ). All the above inhibitors were purchased from Sigma-Aldrich.

For studying the activated signalling pathways, HMSMCs were incubated in DMEM without FCS for $24 \mathrm{~h}$ at $37^{\circ} \mathrm{C}$ in $5 \%$ $\mathrm{CO}_{2}-95 \%$ air humidified atmosphere and then treated with PGF2A for $10 \mathrm{~min}$. The cells were then harvested for western blotting analysis.

\section{Western blotting analysis}

The cells were harvested in the presence of M-Per lysis buffer (Pierce Biotechnology, Rockford, IL, USA). Approximately, 100 mg protein were denatured and separated by SDS (10\%)-PAGE and subsequently transferred to nitrocellulose membranes. The membranes were incubated with specific antibodies including OTR (Santa Cruz Biotechnology, Santa Cruz, CA, USA), CX43 (Santa Cruz, California, USA), PTGS2 (Santa Cruz), p-65 (Abcom Inc., Cambridge, MA, USA), phospho-p65 (ser-529) (Epitomics
Inc., Burlingame, CA, USA), ERK1/2 (Cell Signaling, Danvers, MA, USA), phospho-ERK1/2 (Cell Signaling), NFATC1 (Santa Cruz), p38 (Cell Signaling) and phospho-p38 (Cell Signaling), PI3K (Abcom) and phospho-PI3K (Tyr508) (Santa Cruz) overnight at $4{ }^{\circ} \mathrm{C}$. The membranes were then incubated with a secondary HRP-conjugated antibody and immunoreactive proteins visualised using enhanced chemiluminescence (Santa Cruz). The intensities of light-emitting bands were detected and quantified using Sygene Bio Image system (Synoptics Ltd, Cambridgeshire, UK). To control sampling errors, the ratio of band intensities to $\beta$-actin was obtained to quantify the relative protein expression level for OTR, CX43, OTR and NFATC1. The levels of phosphoPI3K, phospho-p65, phospho-ERK1/2 and phospho-p38 were normalised to the unphosphorylated type of these proteins.

\section{Statistical analysis}

The results for all protein determinations are presented as the mean \pm s.E.M. Individual comparisons were then made by twoway ANOVA followed by the Student-Newman-Keuls multiple comparison method. Significance was achieved at $P \leq 0.05$.

\section{Results}

\section{The signalling pathways involved in PGF2A modulation of CX43 expression}

As mentioned, PTGFR mainly couples with GQ protein and subsequently activates the effector PLC $\beta$ which catalyses the hydrolysis of membrane phosphoinositol lipids, leading to the release of inositol-1,4,5-triphosphate (IP3) and diacylglycerol (DAG). IP3 binding to IP3 receptors (IP3R) can trigger the release of $\mathrm{Ca}^{2}+$ from endoplasmic reticulum (ER), while DAG can activate PKC signalling pathway. At first, we examined the effect of PLC inhibitor on PGF2A modulation of CX43 expression. As shown in Fig. 1A, as expected, PGF2A at $10^{-6} \mathrm{M}$ upregulated CX43 expression. U73122, an inhibitor of PLC, at $10^{-5} \mathrm{M}$ totally reversed PGF2A upregulation of CX43 expression. Application of PKC inhibitor chelerythrine $\left(10^{-5} \mathrm{M}\right)$ could totally reverse PGF2A-induced CX43 expression.

PGF2A can activate PI3K, ERK1/2 and P38 signalling pathways via PLC-dependent and independent pathway. LY294002, an inhibitor of PI3K, at $10^{-5} \mathrm{M}$ did not block PGF2A-induced CX43 expression. PD 98056, an inhibitor of ERK, at $10^{-5} \mathrm{M}$ could totally reverse PGF2A-induced CX43 expression. SB 202190, an inhibitor of P38, at $10^{-5} \mathrm{M}$ also blocked the effect of PGF2A on CX43 expression (Fig. 1B).

It is known that PKC, PI3K and ERK signalling can activate NFKB signalling (Hazeki et al. 2007). We therefore examined whether $N F \kappa B$ signalling pathway is involved in PGF2A-induced CX43 expression. The NFKB inhibitor PDTC $\left(10^{-5} \mathrm{M}\right)$ could totally block the effect of PGF2A on CX43 (Fig. 1B).

GQ/PLC signalling that causes $\mathrm{Ca}^{2+}$ release from intracellular calcium store, subsequently activates 

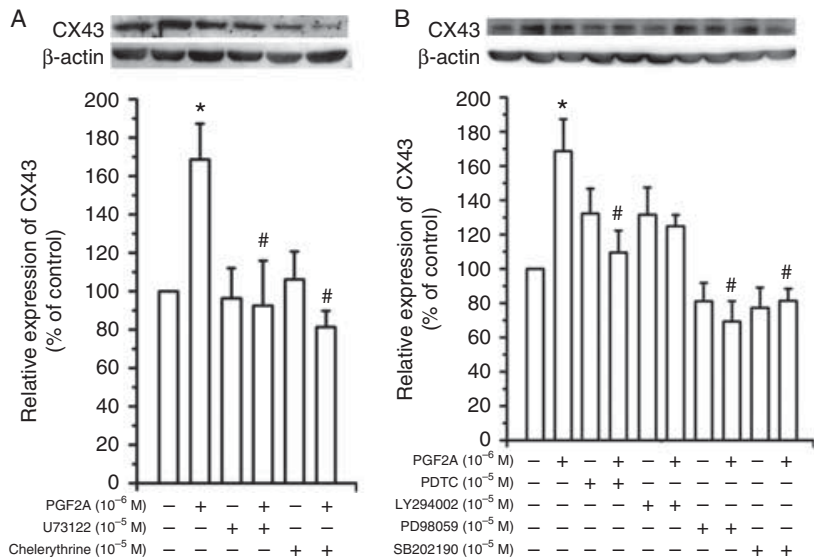

Figure 1 The effects of PLC, PKC, PI3K, ERK, P38 and NFKB inhibitors on PGF2A modulation of CX43 expression. HMSMCs were cultured and followed with the treatment of PLC inhibitor (U73122), PKC inhibitor (chelerythrine), PI3K inhibitor (LY294002), P38 inhibitor (SB202190), ERK inhibitor (PD98059) or NFKB inhibitor (PDTC) in presence or absence of PGF2A $\left(10^{-6} \mathrm{M}\right)$. The cells were harvested and the protein expression of CX43 was determined by western blotting analysis. (A) The effects of U73122 $\left(10^{-5} \mathrm{M}\right)$ and chelerythrine $\left(10^{-5} \mathrm{M}\right)$. (B) The effects of PDTC $\left(10^{-5} \mathrm{M}\right)$, LY294002 $\left(10^{-5} \mathrm{M}\right)$, PD98059 $\left(10^{-5} \mathrm{M}\right)$ and SB202190 $\left(10^{-5} \mathrm{M}\right)$. Representative protein bands were presented on the top of histogram. Values are presented as mean \pm s.E.M. $n=6$ (from six patients). ${ }^{*} P<0.05$ compared with vehicle control. ${ }^{\#} P<0.05$ compared with PGF2A.

calcineurin/nuclear factor of activated T-cells (NFAT) pathway (Sales et al. 2009). We then applied the series of inhibitors to explore the role of calcineurin/NFAT pathway in PGF2A regulation of CX43 expression. As shown in Fig. 2, PGF2A stimulation of CX43 expression was not reversed by administration of calcineurin inhibitor CsA $\left(10^{-5} \mathrm{M}\right)$. The blocker of calcineurin and NFAT interaction Inca- $6\left(10^{-5} \mathrm{M}\right)$ and the inhibitor of NFAT-AP1 complex RA $\left(10^{-5} \mathrm{M}\right)$ did not affect PGF2A-induced CX43 expression. Notably, treatment of cells with RA alone could increase CX43 expression.

\section{The signalling pathways responsible for PGF2A modulation of PTGS2 and OTR expression}

Our previous study has shown that PGF2A robustly stimulates PTGS2 and OTR expression in cultured HMSMCs which were isolated from lower segment (Xu et al. 2011). In the present study, it was also shown that PGF2A at $10^{-6} \mathrm{M}$ significantly enhanced PTGS2 and OTR expression in HMSMCs. PLC inhibitor U73122 $\left(10^{-5} \mathrm{M}\right)$ could totally reverse PGF2A stimulation of PTGS2 and OTR expression (Fig. 3). PKC inhibitor chelerythrine $\left(10^{-5} \mathrm{M}\right)$ did not reverse PGF2A stimulation of OTR expression. Treatment of cells with chelerythrine alone increased PTGS2 expression. There was no significant difference in PTGS2 expression among the cells with chelerythrine $\left(10^{-5} \mathrm{M}\right)$ treatment, PGF2A $\left(10^{-6} \mathrm{M}\right)$ treatment and PGF2A plus chelerythrine treatment.

LY294002 $\left(10^{-5} \mathrm{M}\right)$ could totally block PGF2A upregulation of PTGS2 and OTR expression. SB 202190 at $10^{-5} \mathrm{M}$ also blocked the effect of PGF2A on PTGS2 and OTR. PD98056 $\left(10^{-5} \mathrm{M}\right)$ could totally reverse PGF2A-induced PTGS2 expression but not OTR expression (Fig. 4). PDTC at $10^{-5} \mathrm{M}$ did not block the effect of PGF2A on PTGS2 and OTR. Treatment of cells with PDTC alone enhanced PTGS2 expression but did not affect OTR expression.

The role of calcineurin/NFAT pathway in PGF2A regulation of PTGS2 and OTR expression was then studied. With the administration of calcineurin inhibitor CsA, the robust stimulation of PTGS2 and OTR expression by PGF2A was reversed. The similar trend was confirmed by the application of Inca- 6 and RA (Figs 5 and 6).

\section{PGF2A activates NFAT, NFKB, ERK, P38 and PI3K signalling pathways}

We then confirmed whether PGF2A activates NFAT, $\mathrm{NF} \kappa \mathrm{B}, \mathrm{ERK}$ and $\mathrm{P} 38$ signalling pathways. Five members of the NFAT family of transcription factors have been isolated: NFATC2 (NF-AT1/p), NFATC1 (NF-AT2), NFATC4 (NF-AT3), NFATC3 (NF-AT4/x), and NFAT5

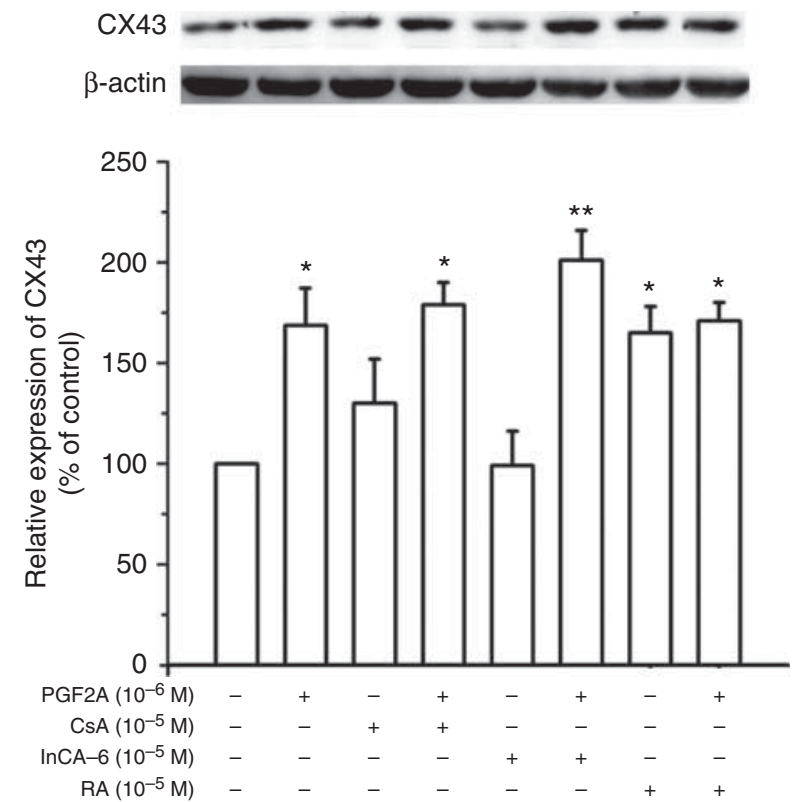

Figure 2 The effects of calcineurin/NFAT pathway inhibitors on PGF2A-induced CX43 expression. HMSMCs were treated with calcineurin inhibitor (CsA), the blocker of calcineurin and NFAT interaction (InCA-6), NFAT-AP1 complex inhibitor (RA) in presence or absence of PGF2A $\left(10^{-6} \mathrm{M}\right)$ for $24 \mathrm{~h}$. The protein expression of CX43 in the cells was determined by western blotting analysis. Representative protein bands were presented on the top of histogram. Data are presented as mean \pm S.E.M. $n=6$ (from six patients). ${ }^{*} P<0.05$, $* * P<0.01$ compared with vehicle control. 
A
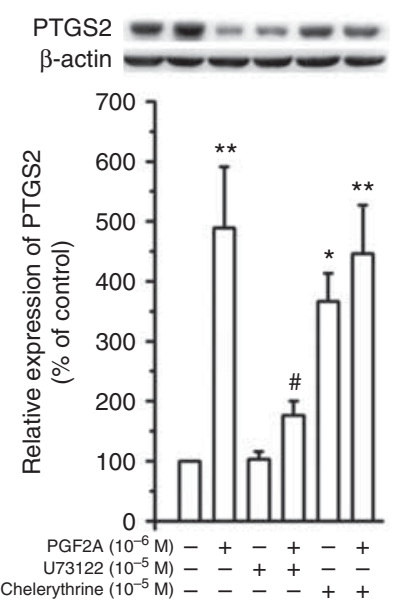

B
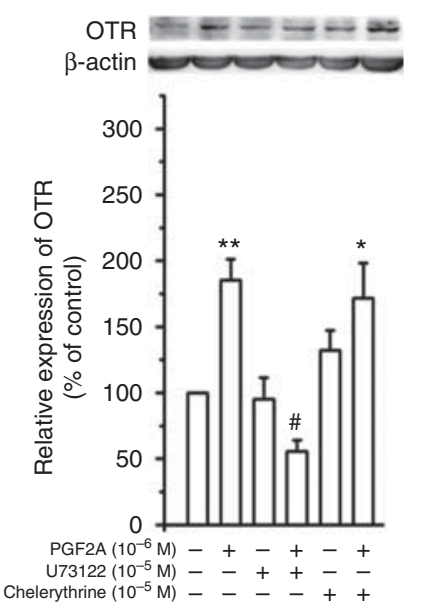

Figure 3 The effects of PLC and PKC inhibitors on PGF2A regulation of PTGS2 and OTR expression. HMSMCs were cultured and followed with the treatment of PLC inhibitor (U73122) or PKC inhibitor (chelerythrine) in the presence or absence of PGF2A $\left(10^{-6} \mathrm{M}\right)$. The cells were harvested and the protein expression of PTGS2 (A) and OTR (B) was determined by western blotting analysis. Representative protein bands were presented on the top of histogram. Data are presented as mean \pm S.E.M. $n=5$ (from five patients). ${ }^{*} P<0.05,{ }^{* *} P<0.01$ compared with vehicle control. ${ }^{\#} P<0.05$ compared with PGF2A.

(TonEBP) (Rao et al. 1997). NFATC1-4 signalling is mediated by the $\mathrm{Ca}^{2+}$ /calmodulin-dependent phosphatase calcineurin, whereas NFAT5 activity is activated by osmotic stress (Rao et al. 1997). Normally, $\mathrm{Ca}^{2+}$ induces the activation of calcineurin, which leads to NFAT dephosphorylation. In human myometrium, NFATC1 has been shown to be activated by $\mathrm{Ca}^{2+}$ signalling (Pont et al. 2012). Thus, we examined whether NFATC1 is activated by PGF2A. For NFKB activation, the level of phospho-p65 was measured. As shown in Fig. 7, treatment of cells with PGF2A $\left(10^{-6} \mathrm{M}\right)$ significantly increased the level of NFATC1. The levels of phosphop65, phospho-ERK1/2, phospho-PI3K and phospho-p38 were also significantly increased by PGF2A.

\section{Discussion}

CX43, PTGS2 and OTR are the key indicators for the activation of uterus and can serve as proxies for uterine activation (Challis et al. 2000). CX43, the major myometrial gap junction protein, is responsible for establishing a low-resistance electrical pathway between cells (Kumar \& Gilula 1996, Miyoshi et al. 1998). PGs are mainly produced within uterus during pregnancy, while PTGS2 is the key limit enzyme for PG synthesis (Caldwell et al. 1973, Lundin-Schiller \& Mitchell 1990, Olson 2003). Oxytocin is a well-known neurohypophysial hormone that facilitates parturition and is commonly used as an uterotonic drug in clinical practice for the treatment of primary postpartum haemorrhage. Many studies have demonstrated that OTR level in myometrium

is much higher at the end of pregnancy, which is critical for the onset of labour (Fuchs et al. 1995, Kimura et al. 1996, Challis et al. 2000) although a few studies reported that OTR expression is not increased with labour (Phaneuf et al. 2000, Havelock et al. 2005). This study confirmed the previous findings that PGF2A upregulates the expression of these proteins in human pregnant myometrium, suggesting that PGF2A is involved in the processes of uterus activation for labour.

As mentioned before, PTGFR mainly couples with GQ protein and subsequently activates PLC $\beta$ which causes the release of IP3 and DAG. IP3 then leads to intracellular $\mathrm{Ca}^{2+}$ flux, which subsequently activates calcineurin/NFAT pathway (Luckas et al. 1999, Sales et al. 2009, Wallace et al. 2011). Moreover, PTGFR can activate multiple signalling pathways including PI3K, ERK1/2 and P38 signalling pathways (Jabbour et al. 2005, Wallace et al. 2011, Kondo et al. 2012). This study showed that PLC inhibitor U73122 could reverse the effects of PGF2A on CX43, PTGS2 and OTR expression, suggesting that robust stimulation of CX43, PTGS2 and OTR by PGF2A requires PLC activation. However, divergent downstream signalling pathways are responsible for PGF2A regulation of CX43, PTGS2 and OTR. For CX43, the inhibitors of PKC, P38 and ERK could totally reverse PGF2A action, whereas the inhibitors of PI3K and calcineurin/NFAT signalling pathways did not reverse PGF2A action on CX43, which suggests that $\mathrm{PGF} 2 \mathrm{~A}$ regulation of $\mathrm{CX} 43$ expression is through PLC/PKC, P38 and ERK pathways. Interestingly, it has been shown that PKC activation leads to an increase in CX43 level in myometrium
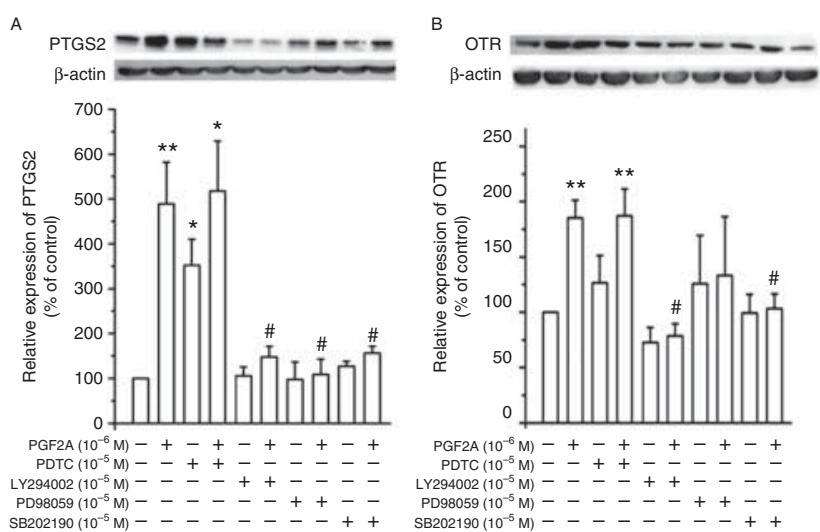

Figure 4 The effects of PLC, PKC, PI3K, ERK, P38 and NFKB inhibitors on PGF2A modulation of PTGS2 and OTR expression. HMSMCs from LS were cultured and followed with the treatment of PI3K inhibitor (LY294002), P38 inhibitor (SB202190), ERK inhibitor (PD98059) or NFאB inhibitor (PDTC) in the presence or absence of PGF2A $\left(10^{-6} \mathrm{M}\right)$. The cells were harvested and the protein expression of PTGS2 (A) and OTR (B) was determined by western blotting analysis. Representative protein bands were presented on the top of histogram. Data are presented as mean \pm s.E.M. $n=5$ (from five patients). ${ }^{*} P<0.05$, ${ }^{* *} P<0.01$ compared with vehicle control. ${ }^{\#} P<0.05$ compared with PGF2A. 


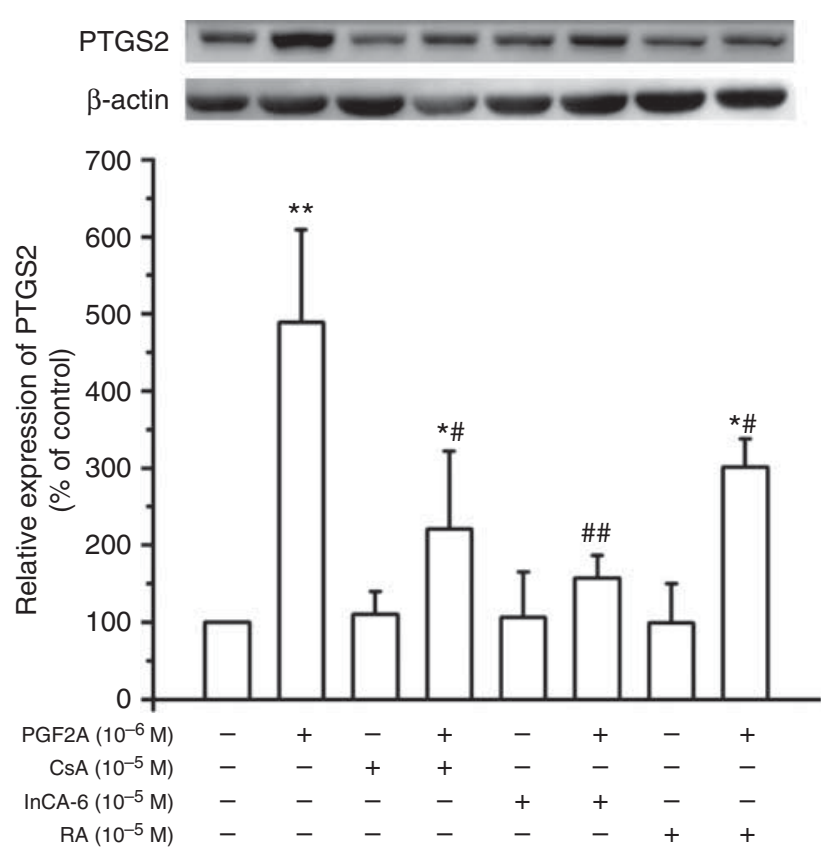

Figure 5 The effects of calcineurin/NFAT pathway inhibitors on PGF2Ainduced PTGS2 expression. HMSMCs were treated with calcineurin inhibitor (CsA), the blocker of calcineurin and NFAT interaction (InCA-6), NFAT-AP1 complex inhibitor (RA) in the presence or absence of PGF2A $\left(10^{-6} \mathrm{M}\right)$ for $24 \mathrm{~h}$. The protein expression of PTGS2 in the cells was determined by western blotting analysis. Representative protein bands were presented on the top of histogram. Data are presented as mean \pm S.E.M. $n=7$ (from seven patients). ${ }^{*} P<0.05$, ${ }^{* *} P<0.01$ compared with vehicle control. ${ }^{\sharp} P<0.05,{ }^{\# \#} P<0.01$ compared with PGF2A.

(Geimonen et al. 1996), while P38 and ERK signalling pathways are involved in CX43 expression in vascular smooth muscle cells (Jia et al. 2007). In addition, our results indicate that the signalling pathways responsible for PGF2A upregulation of PTGS2 and OTR are similar. The inhibitors of P38, PI3K and calcineurin/NFAT blocked the effect of PGF2A on PTGS2 and OTR, suggesting that $\mathrm{PLC} / \mathrm{Ca}^{2+} /$ calcineurin/NFAT, P38 and PI3K signalling pathways contribute to PGF2A stimulation of PTGS2 and OTR expression. A number of studies have demonstrated that multiple signalling pathways are involved in PTGS2 and OTR expression in various tissues. For instance, Sales et al. (2009) demonstrated that PGF2A upregulation of PTGS2 expression is dependent on PLC and ERK1/2 but not PKC signalling pathways in endometrial adenocarcinoma cells. Some studies reported that ERK and P38 MAPK activation induces PTGS2 expression in HMSMCs (Bartlett et al. 1999, Sooranna et al. 2005), and calcineurin/NFAT signalling pathway is involved in PTGS2 expression in human myomentrium (Pont et al. 2012) and endometrial stromal cells (Abraham et al. 2012). For OTR, Sooranna et al. (2007) have demonstrated that activation of P38 signalling leads to an increase in OTR expression in human myometrial cells.
However, there might be a controversy regarding PKC and AP1 modulation of OTR expression. In the promoter region of OTR gene, there are a number of AP1 binding sites (Ball et al. 2006). Some studies reported that phorbol 12-myristate 13-acetate (PMA) increases OTR expression in breast cancer cells and neuroblastoma cells (Bale \& Dorsa 1998). In contrast, Ball et al. (2006) have demonstrated that PKC and AP1 are not involved in OTR expression in an immortalised human myometrial cell line. As mentioned, this study showed that PKC signalling was not involved in PGF2A stimulation of OTR expression, whereas calcineurin/NFAT signalling was involved in PGF2A stimulation of OTR expression. It would suggest that signalling pathways responsible for OTR expression are differed in different cell types.

Notably, this study showed that treatment of the cells with RA alone increased CX43 expression. RA is known to disturb the formation of AP1-NFAT complex and induce dissociation of AP1 complex (Sales et al. 2009). It is therefore used to inhibit calcineurin/NFAT signalling pathways. It has been demonstrated that the promoter of CX43 gene contains a couple of AP1 sites and activation of AP1 induces CX43 expression (Geimonen et al. 1996). Apparently, the stimulatory effect of RA on CX43
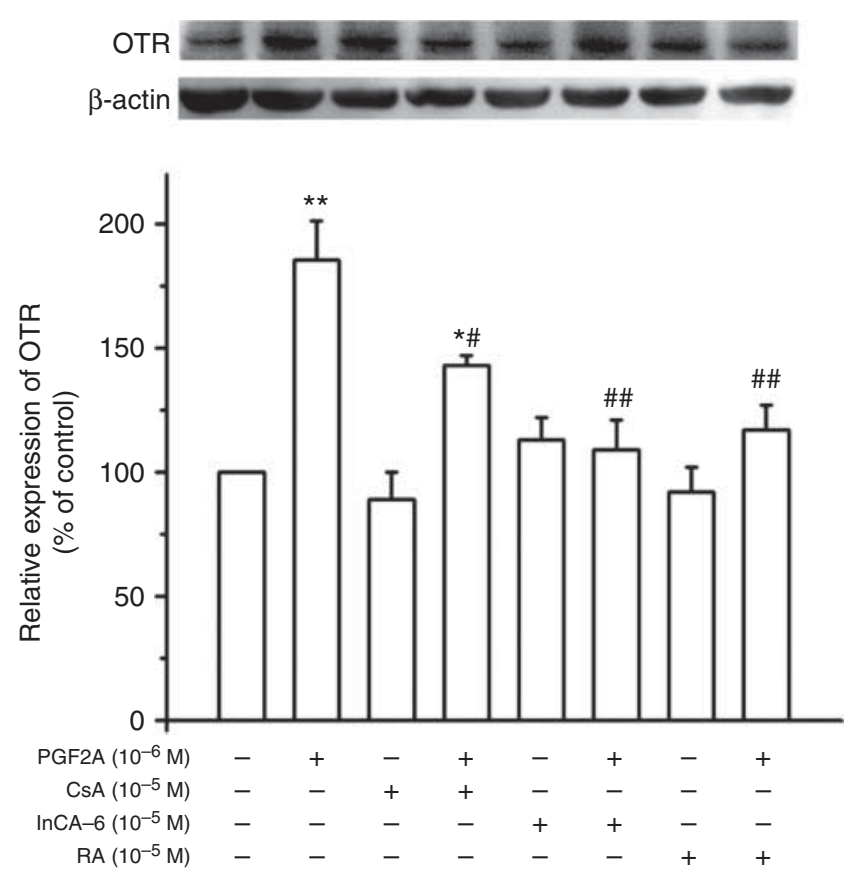

Figure 6 The effects of calcineurin/NFAT pathway inhibitors on PGF2Ainduced OTR expression. HMSMCs were treated with calcineurin inhibitor (CsA), the blocker of calcineurin and NFAT interaction (InCA-6), NFAT-AP1 complex inhibitor (RA) in the presence or absence of PGF2A $\left(10^{-6} \mathrm{M}\right)$ for $24 \mathrm{~h}$. The protein expression of OTR in the cells was determined by western blotting analysis. Representative protein bands were presented on the top of histogram. Data are presented as mean \pm S.E.M. $n=4$ (from four patients). ${ }^{*} P<0.05,{ }^{* *} P<0.01$ compared with vehicle control. ${ }^{\sharp} P<0.05,{ }^{\# \#} P<0.01$ compared with PGF2A $10^{-6} \mathrm{M}$. 

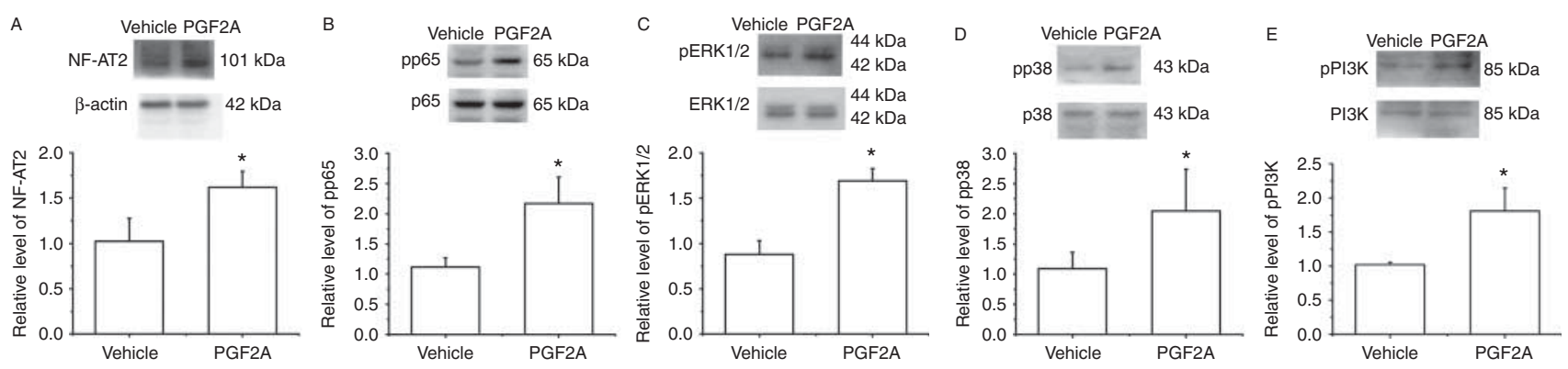

Figure 7 The effects of PGF2A on the levels of NFATC1, phospho-p65, phospho-ERK1/2, phosphor-PI3K and phospho-p38 in myometrium. HMSMCs were treated with PGF2A $\left(10^{-6} \mathrm{M}\right)$ for $10 \mathrm{~min}$. The cells were then harvested for determining the levels of NFATC1(NF-AT2), p65, phospho-p65, ERK1/2, phospho-ERK1/2, p38, phospho-p38, PI3K and phospho-PI3K by western blotting analysis. (A) NFATC1 (NF-AT2) level, (B) p65 level, (C) ERK1/2 level, (D) p38 level, (E) PI3K level. Representative protein bands were presented on the top of histogram. Data are presented as mean \pm s.E.M. $n=3$ (from three patients). ${ }^{*} P<0.05$ compared with vehicle control. pp65, phospho-p65; pERK1/2, phospho-ERK1/2; pp38, phospho-p38; pPI3K, phospho-PI3K.

expression is not through its effect on AP1-NFAT complex. Given that RA can also interact with retinoic acid receptors (Li et al. 2014), whether retinoic acid receptors are involved in CX43 expression is required to be elucidated. In addition, it was also found that treatment of HMSMCs with PKC inhibitor chelerythrine alone increased PTGS2 expression. As mentioned, PKC signalling pathways might not be involved in PTGS2 expression in some cell types (Sales et al. 2009). To our knowledge, there is no study which reports that PKC signalling inhibits PTGS2 expression. There are at least 11 isoforms of PKC, which can induce different functions (Mochly-Rosen et al. 2012). As chelerythrine is a non-selective inhibitor of PKC (Sheng et al. 2008), the isoforms of PKC responsible for inhibition of PTGS2 expression in myometrium remains to be elucidated. In this study, we also found that chelerythrine did not further increase PTGS2 expression in the presence of PGF2A. If different isoforms of PKC have different effects on PTGS2 expression and one of PKC isoforms is involved in PGF2A action, chelerythrine and PGF2A would not have additive effect on PTGS2 expression. Nevertheless, the mechanisms underlying chelerythrine stimulation of PTGS2 expression in myometrium remain to be elucidated in our future experiments.

A number of studies proposed that PGF2A can directly and indirectly activate $\mathrm{NF \kappa B}$ signalling in some tissues (Aten et al. 1998, Taniguchi et al. 2010). The promoter region of CX43 contains NFKB binding sites, suggesting that NFKB activation can stimulate CX43 expression (Echetebu et al. 1999). In this study, we found that NFKB signalling was involved in CX43 expression. Although a number of studies have demonstrated that $N F \kappa B$ activation can stimulate PTGS2 expression in myometrium (Duggan et al. 2007), few studies provide the direct evidence that PGF2A upregulates PTGS2 expression via $\mathrm{NF} \kappa \mathrm{B}$ signalling in myometrial cells. Taniguchi et al. (2010) have shown that PGF2A stimulates PTGS2 expression via NFKB in corpus luteum. However, in this study, NFKB signalling was not involved in PGF2A stimulation of PTGS2 expression. Taken together, it would let us suggest that PGF2A stimulates PTGS2 through different signalling pathways in different types of cells. Some studies have demonstrated that NFKB activation induces OTR expression in myometrium (Khanjani et al. 2011). Herein, we found that NFאB was not involved in PGF2A stimulation of OTR in myometrial cells. Currently, it is hard to explain why NFKB is involved in PGF2A-induced CX43 expression but not in PGF2Ainduced PTGS2 and OTR expression in myometrial cells.

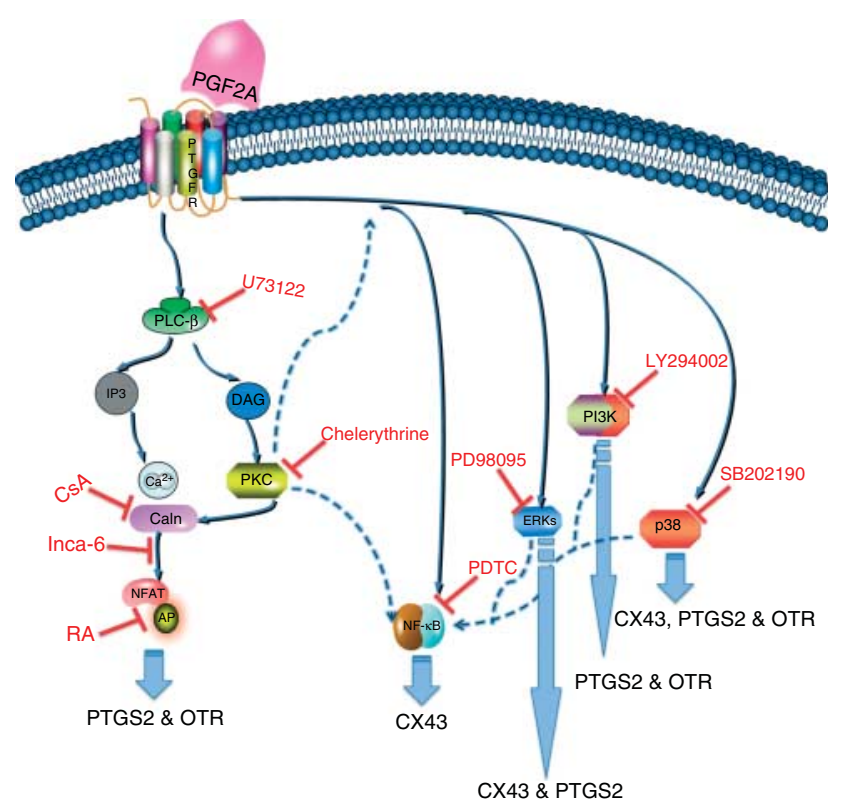

Figure 8 Scheme illustrating the signalling pathway involved in PGF2Ainduced CX43, PTGS2 and OTR expression in myometrium. PTGFR primarily couples to GQ protein and activates PLC $\beta$, which catalyses the hydrolysis of membrane phosphoinositol lipids and leads to the release of IP3 and DAG, subsequently activates PKC and triggers the release of $\mathrm{Ca}^{2+}$ from ER. $\mathrm{Ca}^{2+}$ activates calcineurin/NFAT pathway and eventually activates AP1 signalling. PTGFR also activates PI3K, ERK, P38 signalling pathways. PKC, PI3K, ERK, P38 signaling can lead to activation of NFKB. 
In this study, it was found that PDTC treatment could increase PTGS2 expression. Our previous study has shown that PDTC can inhibit corticotropin-releasing hormone activation of NFKB in HMSMCs (You et al. 2014). However, PDTC has also been shown to induce P38 activation in various cells, such as vascular smooth muscle cells, hepatocytes and thymocytes (Moon et al. 2004). Further experiments are required to investigate whether P38 signalling mediates PDTC stimulation of PTGS2 expression in myometrium.

In conclusion, this study has demonstrated that PGF2A stimulates CX43, PTGS2 and OTR in human pregnant myometrium. Divergent signalling pathways are involved in PGF2A modulation of CX43, PTGS2 and OTR in myometrium (Fig. 8).

\section{Declaration of interest}

The authors declare that there is no conflict of interest that could be perceived as prejudicing the impartiality of the research reported.

\section{Funding}

This work was supported by National Science Foundation of China (nos 31101067 and 81170596), Science and Technology Commission of Shanghai Municipals (13430722900) and the Global Alliance for the Prevention of Prematurity and Stillbirth (GAPPS): Preventing Preterm Birth Initiative.

\section{Acknowledgements}

The authors wish to thank the nursing and medical staff of the delivery suite, and the patients at Changhai Hospital and Maternity and Child Health Hospital of Pudong New District, Shanghai, China for their participation.

\section{Reference}

Abraham F, Sacerdoti F, De León R, Gentile T \& Canellada A 2012 Angiotensin II activates the calcineurin/NFAT signaling pathway and induces cyclooxygenase-2 expression in rat endometrial stromal cells. PLOS ONE 7 e37750. (doi:10.1371/journal.pone.0037750)

Aten RF, Kolodecik TR, Rossi MJ, Debusscher C \& Behrman HR 1998 Prostaglandin F2 $\alpha$ treatment in vivo, but not in vitro, stimulates protein kinase C-activated superoxide production by nonsteroidogenic cells of the rat corpus luteum. Biology of Reproduction 59 1069-1076. (doi:10.1095/biolreprod59.5.1069)

Bale TL \& Dorsa DM 1998 NGF, cyclic AMP, and phorbol esters regulate oxytocin receptor gene transcription in SK-N-SH and MCF7 cells. Brain Research. Molecular Brain Research 53 130-137. (doi:10.1016/S0169328X(97)00287-8)

Ball A, Wang JW, Wong S, Zielnik B, Mitchell J, Wang N, Stemerman MB \& Mitchell BF 2006 Phorbol ester treatment of human myometrial cells suppresses expression of oxytocin receptor through a mechanism that does not involve activator protein-1. American Journal of Physiology. Endocrinology and Metabolism 291 E922-E928. (doi:10.1152/ajpendo. 00602.2005)

Bartlett SR, Sawdy R \& Mann GE 1999 Induction of cyclooxygenase-2 expression in human myometrial smooth muscle cells by interleukin-1 $\beta$ : involvement of $\mathrm{p} 38$ mitogen-activated protein kinase. Journal of Physiology 520 399-406. (doi:10.1111/j.1469-7793.1999.00399.x)
Caldwell BV, Auletta FJ \& Speroff L 1973 Prostaglandins in the control of ovulation, corpus luteum function, and parturition. Journal of Reproductive Medicine 10 133-138.

Challis JRG, Matthews SG, Gibb W \& Lye SJ 2000 Endocrine and paracrine regulation of birth at term and preterm. Endocrine Reviews 21 514-550. (doi:10.1210/edrv.21.5.0407)

Christiaens I, Zaragoza DB, Guilbert L, Robertson SA, Mitchell BF \& Olson DM 2008 Inflammatory processes in preterm and term parturition. Journal of Reproductive Immunology 791 50-57. (doi:10.1016/j.jri. 2008.04.002)

Duggan SV, Lindstrom T, Iglesias T, Bennett PR, Mann GE \& Bartlett SR 2007 Role of atypical protein kinase $C$ isozymes and NF- $\kappa B$ in IL-1 $\beta$ induced expression of cyclooxygenase- 2 in human myometrial smooth muscle cells. Journal of Cellular Physiology 210 637-643. (doi:10.1002/ jcp.20901)

Echetebu CO, Ali M, Izban MG, MacKay L \& Garfield RE 1999 Localization of regulatory protein binding sites in the proximal region of human myometrial connexin 43 gene. Molecular Human Reproduction 5 757-766. (doi:10.1093/molehr/5.8.757)

Fuchs AR, Fields MJ, Freidman S, Shemesh M \& Ivell R 1995 Oxytocin and the timing of parturition. Influence of oxytocin receptor gene expression, oxytocin secretion, and oxytocin-induced prostaglandin F2 $\alpha$ and E2 release. Advances in Experimental Medicine and Biology 395 405-420.

Geimonen E, Jiang W, Ali M, Fishman GI, Garfield RE \& Andersen J 1996 Activation of protein kinase $C$ in human uterine smooth muscle induces connexin-43 gene transcription through an AP-1 site in the promoter sequence. Journal of Biological Chemistry 271 23667-23674. (doi:10.1074/jbc.271.39.23667)

Havelock JC, Keller P, Muleba N, Mayhew BA, Casey BM, Rainey WE \& Word RA 2005 Human myometrial gene expression before and during parturition. Biology of Reproduction 72 707-719. (doi:10.1095/biolreprod.104.032979)

Hazeki K, Nigorikawa K \& Hazeki O 2007 Role of phosphoinositide 3-kinase in innate immunity. Biological \& Pharmaceutical Bulletin 30 1617-1623. (doi:10.1248/bpb.30.1617)

Jabbour HN, Sales KJ, Boddy SC, Anderson RA \& Williams AR 2005 A positive feedback loop that regulates cyclooxygenase-2 expression and prostaglandin $\mathrm{F} 2 \alpha$ synthesis via the F-series-prostanoid receptor and extracellular signal-regulated kinase 1/2 signaling pathway. Endocrinology 146 4657-4664. (doi:10.1210/en.2005-0804)

Jia G, Mitra AK, Cheng G, Gangahar DM \& Agrawal DK 2007 Angiotensin II and IGF-1 regulate connexin43 expression via ERK and p38 signaling pathways in vascular smooth muscle cells of coronary artery bypass conduits. Journal of Surgical Research 142 137-142. (doi:10. 1016/j.jss.2006.11.007)

Kamel RM 2010 The onset of human parturition. Archives of Gynecology and Obstetrics 281 975-982. (doi:10.1007/s00404-010-1365-9)

Khanjani S, Terzidou V, Lee YS, Thornton S, Johnson MR \& Bennett PR 2011 Synergistic regulation of human oxytocin receptor promoter by CCAAT/ enhancer-binding protein and RELA. Biology of Reproduction 85 1083-1088. (doi:10.1095/biolreprod.111.092304)

Kimura T, Takemura $M$, Nomura $S$, Nobunaga T, Kubota $Y$, Inoue $T$, Hashimoto K, Kumazawa I, Ito Y, Ohashi K et al. 1996 Expression of oxytocin receptor in human pregnant myometrium. Endocrinology 137 780-785. (doi:10.1210/endo.137.2.8593830)

Kinoshita K, Satoh K \& Sakamoto S 1977 Prostaglandin F2 $\alpha$ and E1 in plasma and amniotic fluid during human pregnancy and labor. Endocrinologia Japonica 24 155-162. (doi:10.1507/endocrj1954.24.155)

Kondo A, Otsuka T, Kato K, Natsume H, Kuroyanagi G, Mizutani J, Ito Y, Matsushima-Nishiwaki R, Kozawa O \& Tokuda H 2012 AMP-activated protein kinase inhibitor decreases prostaglandin F2 $\alpha$-stimulated interleukin-6 synthesis through p38 MAP kinase in osteoblasts. International Journal of Molecular Medicine 30 1487-1489. (doi:10.3892/ijmm.2012. 1159)

Kumar NM \& Gilula NB 1996 The gap junction communication channel. Cell 84 381-388. (doi:10.1016/S0092-8674(00)81282-9)

Li M, Sun Y, Guan X, Shu X \& Li C 2014 Advanced progress on the relationship between $\mathrm{RA}$ and its receptors and malignant tumors. Critical Reviews in Oncology/Hematology 91 271-282. (doi:10.1016/ j.critrevonc.2014.04.001) 
Luckas MJ, Taggart MJ \& Wray S 1999 Intracellular calcium stores and agonist-induced contractions in isolated human myometrium. American Journal of Obstetrics and Gynecology 181 468-476. (doi:10.1016/ S0002-9378(99)70580-6)

Lundin-Schiller S \& Mitchell MD 1990 The role of prostaglandins in human parturition. Prostaglandins, Leukotrienes, and Essential Fatty Acids 39 1-10. (doi:10.1016/0952-3278(90)90164-G)

Miyoshi H, Boyle MB, MacKay LB \& Garfield RE 1998 Gap junction currents in cultured muscle cells from human myometrium. American Journal of Obstetrics and Gynecology 178 588-593. (doi:10.1016/ S0002-9378(98)70443-0)

Mochly-Rosen D, Das K \& Grimes KV 2012 Protein kinase C, an elusive therapeutic target? Nature Reviews. Drug Discovery 11 937-957. (doi:10.1038/nrd3871)

Moon SK, Jung SY \& Kim CH 2004 Transcription factor Sp1 mediates p38MAPK-dependent activation of the p21WAF1gene promoter in vascular smooth muscle cells by pyrrolidine dithiocarbamate. Biochemical and Biophysical Research Communications 316 605-611. (doi:10.1016/j.bbrc.2004.02.096)

Olson DM 2003 The role of prostaglandins in the initiation of parturition. Best Practice \& Research. Clinical Obstetrics \& Gynaecology 17 717-730. (doi:10.1016/S1521-6934(03)00069-5)

Phaneuf S, Rodríguez Liñares B, TambyRaja RL, MacKenzie IZ \& López Bernal A 2000 Loss of myometrial oxytocin receptors during oxytocininduced and oxytocin-augmented labour. Journal of Reproduction and Fertility 120 91-97. (doi:10.1530/jrf.0.1200091)

Pont JN, McArdle CA \& Bernal LA 2012 Oxytocin-stimulated NFAT transcriptional activation in human myometrial cells. Molecular Endocrinology 26 1743-1756. (doi:10.1210/me.2012-1057)

Rao A, Luo C \& Hogan PG 1997 Transcription factors of the NFAT family: regulation and function. Annual Review of Immunology 15 707-747. (doi:10.1146/annurev.immunol.15.1.707)

Romero R, Munoz H, Gomez R, Parra M, Polanco M, Valverde V, Hasbun J, Garrido J, Ghezzi F, Mazor M et al. 1996 Increase in prostaglandin bioavailability precedes the onset of human parturition. Prostaglandins, Leukotrienes, and Essential Fatty Acids 54 187-191. (doi:10.1016/ S0952-3278(96)90015-0)

Sales KJ, Maldonado-Perez D, Grant V, Catalano RD, Wilson MR, Brown P, Williams AR, Anderson RA, Thompson EA \& Jabbour HN 2009 Prostaglandin $\mathrm{F}(2 \alpha)$-F-prostanoid receptor regulates CXCL8 expression in endometrial adenocarcinoma cells via the calcium-calcineurin-NFAT pathway. Biochimica et Biophysica Acta 1793 1917-1928. (doi:10.1016/ j.bbamcr.2009.09.018)

Sheng H, Zhang Y, Sun J, Gao L, Ma B, Lu J \& Ni X 2008 Corticotropinreleasing hormone $(\mathrm{CRH})$ depresses $n$-methyl-D-aspartate receptormediated current in cultured rat hippocampal neurons via $\mathrm{CRH}$ receptor type 1. Endocrinology 149 1389-1398. (doi:10.1210/en.2007-1378)
Sooranna SR, Engineer N, Loudon JA, Terzidou V, Bennett PR \& Johnson MR 2005 The mitogen-activated protein kinase dependent expression of prostaglandin $\mathrm{H}$ synthase-2 and interleukin-8 messenger ribonucleic acid by myometrial cells: the differential effect of stretch and interleukin-1 $\beta$. Journal of Clinical Endocrinology and Metabolism 90 3517-3527. (doi:10.1210/jc.2004-1390)

Sooranna SR, Engineer N, Liang Z, Bennett PR, Johnson MR \& Imperial College Parturition Research Group 2007 Stretch and interleukin $1 \beta$ : pro-labour factors with similar mitogen-activated protein kinase effects but differential patterns of transcription factor activation and gene expression. Journal of Cellular Physiology 212 195-206. (doi:10.1002/ jcp. 21019)

Sykes L, Maclntyre DA, Teoh TG \& Bennett PR 2014 Anti-inflammatory prostaglandins for the prevention of preterm labour. Reproduction 148 R29-R40. (doi:10.1530/REP-13-0587)

Taniguchi K, Matsuoka A, Kizuka F, Lee L, Tamura I, Maekawa R, Asada H, Taketani T, Tamura H \& Sugino N 2010 Prostaglandin F2 $\alpha$ (PGF2 $\alpha$ ) stimulates PTGS2 expression and PGF2 $\alpha$ synthesis through NFKB activation via reactive oxygen species in the corpus luteum of pseudopregnant rats. Reproduction 140 885-892. (doi:10.1530/REP10-0240)

Wallace AE, Catalano RD, Anderson RA \& Jabbour HN 2011 Chemokine (C-C) motif ligand 20 is regulated by $\operatorname{PGF}(2 \alpha)$-F-prostanoid receptor signalling in endometrial adenocarcinoma and promotes cell proliferation. Molecular and Cellular Endocrinology 331 129-135. (doi:10.1016/j.mce.2010.08.018)

Xu C, Gao L, You X, Dai L, Li Y, Gu H, Slater DM, Olson DM \& Ni X 2011 $\mathrm{CRH}$ acts on $\mathrm{CRH}-\mathrm{R} 1$ and $-\mathrm{R} 2$ to differentially modulate the expression of large-conductance calcium-activated potassium channels in human pregnant myometrium. Endocrinology 152 4406-4417. (doi:10.1210/en. 2011-0262)

Xu C, Long A, Fang X, Wood SL, Slater DM, Ni X \& Olson DM 2013 Effects of PGF2 $\alpha$ on the expression of uterine activation proteins in pregnant human myometrial cells from upper and lower segment. Journal of Clinical Endocrinology and Metabolism 98 2975-2983. (doi:10.1210/jc. 2012-2829)

You X, Liu J, Xu C, Liu W, Zhu X, Li Y, Sun Q, Gu H \& Ni X 2014 Corticotropin-releasing hormone $(\mathrm{CRH})$ promotes inflammation in human pregnantmyometrium: the evidence of $\mathrm{CRH}$ initiating parturition? Journal of Clinical Endocrinology and Metabolism 99 E199-E208. (doi:10.1210/jc.2013-3366)

Received 14 September 2014

First decision 30 September 2014

Accepted 22 October 2014 